\title{
Engagement in Multiple Roles: An Investigation of the Student-Work Relationship
}

\author{
Richard Buda and Janet A. Lenaghan \\ Hofstra University
}

\begin{abstract}
This study of 360 undergraduate business school students investigates the impact of the added role of paid worker to a student's well-being as well as role balance, role quality and role conflict. The extension of the work-family literature provided the theoretical underpinnings of the relationship between multiple roles and student success. Tests of the hypotheses provided strong support for the depletion argument of interrole conflict. Implications of the results on student learning and education, as well as for organizations, are discussed and suggestions for future research presented.
\end{abstract}

\section{Introduction}

The need for college students to engage in work as paid employees has been increasing over the last several decades. As the cost of education increases, student activities have become increasingly more complex. Students must often engage in multiple roles in order to fulfill financial, educational, and life requirements. For example, scholarships and financial aid may no longer be sufficient to cover the cost of tuition. Students may find themselves engaging in the added role of paid employee, as well as the traditional student participation roles in organized sports, clubs, fraternities and sororities, student government, etc. The financial burden of pursuing a college education has fallen on the student. Often, parents simply cannot pay or choose not to pay in full. As a result of the increased prevalence of employment obligations in the life of many college students, motivating them to engage in their schoolwork has become a greater challenge for educators.

In addition to the traditional student roles and the role of a paid worker, it is not uncommon for college students to have other commitments, such as marriage and parenting, while pursuing their education. Furthermore, the demographics of college enrollment have changed. Considerable and significant elements of the student body in many institutions of higher learning are non-traditional students. Therefore, within the context of being a student, much of the student-body is engaged in multiple roles. It is the engagement in other roles that may have an impact on one's motivation to engage in schoolwork and therefore become a source of interrole conflict.

This study investigates the multiple roles in which students are increasingly engaged. We are particularly interested in the role of a paid worker. We believe that work is a great resource drain on a college student's time and energy, thus serving as a source of interrole conflict.

Educational researchers have investigated the effects of multiple roles on educators and administrators, but very few studies have attended to the college student 
population. In this research we focus on work-student role conflict to explore whether multiple roles are beneficial to the student's well-being as well as the importance of role balance, role quality and role conflict in the relationship. The few studies that exist will be reviewed. The absence, however, of a theoretical foundation for college students on this subject directs us to look to the work-family literature on multiple roles for much of its theoretical foundation. We will also test role conflict theory in terms of whether being a student interferes with work or, vice-versa, whether work interferes with being a student. Researchers have posited two competing arguments, depletion and enrichment, that have been used to address the dynamics of these multiple roles.

\section{Theory and Hypothesis}

\section{Depletion Argument}

The depletion argument of interrole conflict, according to Kahn, Wolf, Quinn, Snoek and Rosenthal (1964, p.19), is defined as the "simultaneous occurrence of two (or more) sets of pressures such that compliance with one would make more difficult compliance with another." Opposing pressures arise from engaging in multiple roles, and these pressures can be incompatible by requiring different roles to compete for a person's limited time resources as well as the strains associated with one or more roles (Kopelman, Greenhaus \& Connolly, 1983). The assumption underlining the depletion argument is that multiple demands of paid worker and student roles are detrimental to the individual and that role participation invokes stress, resulting in emotional strain (Rothbard, 2001).

Multiple roles may compete for a person's time where time spent on activities within one role cannot be devoted to activities within another role (Greenhaus \& Beutell, 1985). As Lobel (1991) discusses, this utilitarian view of role investment suggests that one role is pitted against another thereby creating a win-loss equation - - time invested in one role depletes time devoted to another. This may occur in two different ways. First, time pressures associated with one role may make it physically impossible to comply with expectations from another role. Second, time pressures may also produce a preoccupation with one role while attempting to meet the demands of another role (Bartolome \& Evans, 1979). According to Greenhaus and Beutell, role demands may not be met if a person is physically absent from a role or is mentally preoccupied with another role. As a result, time-based role conflict incorporates resource drain as the transfer of time or attention between roles. In addition, a recent study by Rothbard and Edwards (2003), suggests that people not only seek pleasure but also invest time coping with role displeasure. The depletion argument draws on work-family research that examines the conflict that work and family roles bring to an individual's life. Individuals become engaged in roles by responding to role demands. The engagement in the role causes strain. Strain is often conceptualized as a negative emotional response to stress that may result in depression or negative affect (Rothbard, 2001). In fact, Stoeva, Chiu and Greenhaus (2002) found that negative affect indirectly affected work-family conflict through its impact on job stress and indirectly affected family-work conflict through its impact on family stress. In addition, Bruck and Allen (2003) found that negative affectivity was most consistently related to various types of conflict. If one 
transfers the depletion hypothesis to the work-student domain, then the more hours one spends on roles associated with work and student domains, the more conflict one would perceive. The basic assumption that the more hours expended on multiple roles will produce more conflict and, therefore, higher feelings of strain. This leads to the first hypothesis.

Hypothesis 1: The more time students engage in work while attending college, the less they will report feelings of well being (strain conflict).

Strain based conflict exists when strain in one role affects performance in another role. The incompatibility created by one role makes it difficult to comply with other roles (Pleck, Staines, \& Lang, 1980). According to Edwards and Rothbard (2000) strain based conflict occurs when participation in one role produces strain that hampers role performance in another role. This definition implies that any work or school role characteristic that produces strain can contribute to a work-school conflict in college students. Also, there is some evidence that college student's expectations may play a role in work-school conflict. Barnett, Gareis, James and Steele (2003) found that college seniors whose mothers worked outside the home while they were children would express less concern about career-marriage conflict than those seniors whose mothers who did not work outside the home. In addition, seniors' expectations about the timing of their marriages and childbearing related to their concerns about careermarriage conflict (Barnett, et al., 2003). The role conflict comes from within the individual in the form of strain or stress that is internal. Often it is described as feelings of well-being.

Individuals may, however, work long hours and benefit psychologically if the work is satisfying. Greenberger and O'Neil (1993) found high levels of role satisfaction associated with low levels of depression and anxiety. The results of an analysis regressing men's stress related physical health problems on their subjective experiences in the paid worker role and the family role support the view that role quality is important (Barnett, Marshall, \& Pleck, 1992).

Hypothesis 2a: There will be a significant positive relationship between the number of hours engaged in the student role and student satisfaction and role quality.

Hypothesis $2 \mathrm{~b}$ : There will be a significant negative relationship between time engaged in the role of paid worker and student satisfaction.

\section{Enrichment Argument}

The enrichment process is an expanding theory of multiple roles which postulates that the available supply of energy to all of us is abundant and expandable. Some roles may be performed without any net energy loss and indeed may even create energy use in that role or other roles (Goode, 1960). Marks (1977) enumerated the following four points on the enrichment (expansion) process: 1) Rather than energy simply flowing out mechanically in response to role demands, individuals try to decide how to use their energy and which role will be honored. 2) People withhold the full flow of energy into a 
given role, thereby freeing energy for other roles. 3) Feelings of energy loss are more of a function of role balance. 4) In the long run we have ample energy for all of our roles regardless of energy expenditures.

The enrichment process, as postulated by Marks (1977), suggests that as an individual increases his/her number of roles there is a gain or benefit from them (enrichment) rather than experiencing depletion. In addition, the enrichment argument assumes that the benefits of multiple roles outweigh the costs leading to gratification rather than strain (Rothbard, 2000). Social identity theory suggests role conflict can be avoided if the individual's values are similar in different roles (Lobel, 1991). Balance is achieved, in Lobel's terms, when there is self consistency across roles.

This enrichment process remains relatively unexplored in the literature. However, Barnett \& Hyde (2001) present a review of the literature on the beneficial effects of multiple roles as it pertains to work and family issues. Their conclusions were that both men and women had benefited by engaging in multiple roles in terms of their mental health. Marks and MacDermid (1996) demonstrated that people with more balanced role systems will report less strain, more role-ease, greater well-being, and more positive role specific experience than people with less balanced role systems.

Role balance is a general orientation across roles. It is both a behavioral pattern of acting across roles in a certain way and a corresponding cognitive affect pattern of organizing one's inner life (Marks \& MacDermid, 1996). Barnett \& Baruch (1985) defined role balance as a measure of role quality and concluded that the quality of experience in work and parental roles was a significant predictor of role overload, and the quality of parental role experience was a significant predictor of role conflict as well as anxiety. Researchers are now attending more to role quality than to role occupancy (Barnet and Hyde, 2001). It is very likely that two or more individuals may occupy similar roles yet experience the quality of each role differently.

Hypothesis 3: There will be a significant negative relationship between well-being and both the number of roles and role balance.

The depletion argument posits, the more hours one spends on roles associated with work and student domains, the more conflict one would perceive. Role expectations may indicate which roles may be perceived more problematic in terms of strain or stress. For example, males may find that being a paid employee while attending college is a better fit to the male role stereotype of being a provider. Females may find that the role of being a student closer to the female gender role stereotype.

Hypothesis 4: In general, the more hours a student spends in work activities and the more they experience role balance (quality), the less he or she should experience work interfering with school activities (WIS).

Hypothesis 5: In general, the more hours a student spends in school activities and the more he or she experiences role balance (quality) the less he or she should experience school activities interfering with work (SIW). 
Hypothesis 6: Undergraduate students who are paid workers will report more work interfering with school than school interfering with work.

\section{Method}

\section{$\underline{\text { Participants }}$}

The data was collected as part of a Quality of Academic Life Study at a university in the North East. The sample consisted of 360 undergraduate students enrolled in a BBA program. Of the 360 students, 184 are male and 176 female; 334 single, 17 married, and 5 parents. The average age of the sample was 22.72. There were 189 seniors, 108 juniors, 32 sophomores, and 31 freshmen in the sample; while 305 were full time and 55 part-time students. 89 lived on campus, 86 lived off campus, and 183 lived at home. Of the 360,93 were employed fulltime (35 hours or more), 184 part time, and 83 were not paid employees.

\section{Procedure}

Since it was important to have students in the study that worked, the data was collected at two different times in ten separate classes in a school of business. Six of the administrations of the Quality of Academic Life Survey were in day classes and 4 administrations were in evening classes. There was no subject loss or attrition rate since it was a one-time collection and whoever was attending class that day received the survey. All participants were volunteers and received no incentives to participate. They were given instructions by the authors which included guarantees of anonymity, how to use the scales, and instructions to return the completed surveys to a specific student, face down, who would then insert the surveys in an envelope and seal it. When the instructions were complete the authors and professor left the classroom leaving the students alone to complete the surveys. The length of time of administration of the survey was approximately 20-25 minutes.

\section{$\underline{\text { Measures }}$}

\section{Well-Being (Role Strain)}

The General Well-Being Scale (GWB), developed for the National Center for Health Statistics, is a structured instrument for assessing self-representations of subjective well-being. Scale scores run from 14 (lowest well-being) to 134 (highest well being) for the first 18 items as described by Fabio (1977). A five or six point Likert type scale is used to collect responses to items such as "How have you been feeling in general?". Scale norms are available from a sample of 79 male and 119 female students at the University of Wisconsin, Milwaukee, in a freshman psychology class (Fazio). Mean scores for the first 18 items of the schedule were 75 for men and 71 for women. (SD = 15 and 18). Internal consistency reliability (Chronbach's alpha) was .91 for men and .95 for women. 
$\underline{\text { Role quality }}$

Two measures of role quality were taken on this sample. For each of the roles identified by the student, a satisfaction score was obtained by asking them to respond to the statement "Overall, how satisfied are you with this role." A seven point Likert type scale ( 1 = Completely Dissatisfied, 7 = Completely Satisfied) was used to collect the data. Satisfaction data was collected on the roles of student, paid worker, spouse, parent, student athlete, and student leader.

$\underline{\text { Role balance (Quality) }}$

The second indicator of role quality was measured by The Role Balance Scale which is comprised of an eight item Likert type scale to which the participants are to respond on a 5-point scale whether they strongly agree (1) to strongly disagree (5) with each item (Marks \& McDermid, 1996). The items orient the respondent to different nuances of the role balance construct such as enjoyment across roles, the balance of attention, the distribution of importance, the balance of satisfaction across roles, and the balance of effort. Often role balance has been used as a measure of role quality as well. Cronbach's alpha for the eight items was .68.

$\underline{\text { Role conflict }}$

Work-student conflict is a modified version of an instrument that measured work-family conflict developed by Kopelman, Greenhaus and Connoly (1983). The student role was substituted for references to the family role used in the original instrument. Four items assessed whether work interferes with being a student (WIS) and another four items assessed whether being a student interferes with work (SIW). The participants' options for both scales were 5-point scales ranging from strongly agree (1) to strongly disagree (5). Cronbach's alpha for WIS was .81 and for SIW .79.

\section{Results}

\section{Tests of Hypotheses}

Before results were generated, tests of linearity were conducted on all relationships under investigation and the results indicated that there were no non-linear relationships. In addition, a power analysis indicated that all statistical tests had sufficient power to detect significant relationships beyond the .05 level.

Table 1 presents the results of hypotheses 1,2 , and 3 . Table 2 presents the results of hypotheses 4 , and 5 . The presentation of the results of this study is organized in this order. 
Table 1:Intercorrelations Between the Study Variables among All Student's. $=360$ )

\begin{tabular}{|c|c|c|c|c|c|c|c|c|c|c|}
\hline Variable & $\begin{array}{l}\text { Mea } \\
\mathrm{n}\end{array}$ & s.d. & 1 & 2 & 3 & 4 & 5 & 6 & 7 & 8 \\
\hline 1. Well-Being & $\begin{array}{l}69.6 \\
5\end{array}$ & 5.23 & - & & & & & & & \\
\hline 2. Time Worked & $\begin{array}{l}27.8 \\
3\end{array}$ & $\begin{array}{l}12.8 \\
8\end{array}$ & $\begin{array}{l}- \\
.13 \\
*\end{array}$ & - & & & & & & \\
\hline $\begin{array}{l}\text { 3. Time Being a } \\
\text { Student }\end{array}$ & $\begin{array}{l}20.0 \\
7\end{array}$ & $\begin{array}{l}16.3 \\
9\end{array}$ & -.07 & $\overline{-}^{-14^{*}}$ & - & & & & & \\
\hline 4. Work Satisfaction & 4.94 & 1.28 & -.02 & -.01 & $\begin{array}{l}- \\
.1 \\
2\end{array}$ & - & & & & \\
\hline $\begin{array}{l}\text { 5. Student } \\
\text { Satisfaction }\end{array}$ & 5.01 & 1.20 & -.05 & $\begin{array}{l}- \\
*\end{array}$ & $\begin{array}{l}.0 \\
9\end{array}$ & .11 & - & & & \\
\hline 6. WIS & 3.03 & .86 & .02 & $\begin{array}{l}- \\
.32^{*}\end{array}$ & $\begin{array}{l}.0 \\
8\end{array}$ & $.18^{*}$ & $.21^{*}$ & - & & \\
\hline 7. SIW & 3.29 & .89 & .04 & .10 & $\begin{array}{l}- \\
.0 \\
6\end{array}$ & $.15^{*}$ & $.15^{\star}$ & $.40^{*}$ & - & \\
\hline 8. Number of Roles & 2.02 & .69 & .00 & .02 & $\begin{array}{l}- \\
.0 \\
4\end{array}$ & .01 & .07 & $\begin{array}{l}- \\
.16^{*}\end{array}$ & -.02 & - \\
\hline 9. Role Quality & $\begin{array}{l}21.4 \\
1\end{array}$ & 3.17 & -.09 & $.13^{*}$ & $\begin{array}{l}.0 \\
7\end{array}$ & $\begin{array}{l}- \\
.21^{*}\end{array}$ & $-12^{*}$ & -.09 & $\begin{array}{l}- \\
.14^{*}\end{array}$ & .01 \\
\hline
\end{tabular}

Note: All tests are two-tailed. ${ }^{*} P<.05 .{ }^{* *} p<.01$.

An examination of Table 1 indicates that as the time worked increases among students, feelings of well-being decrease $(r=-13, p<.05)$. Hypothesis 1 lends some credence to the depletion argument by supporting the notion that the investment of more time in one role can cause role strain (feelings of less well-being) as it depletes time available for other roles.

Hypothesis 2a did not produce significant findings between the number of hours engaged in the student role and student satisfaction and role quality. It appears as 
students put more time in being a student their perception of satisfaction and role quality does not change much.

Hypothesis $2 \mathrm{~b}$ investigated the relationship between time engaged in the role of paid worker and student satisfaction. Table 1 indicates that time spent being a paid worker is negatively related student satisfaction, $(r=-.24, p<.01)$. This finding lends some support for the depletion argument in that the more time a student spends at work the less satisfied he or she is going to be in their other roles.

Hypothesis 3 did not produce a significant relationship between the number of roles one engages in and well-being $(r=.02$, ns.) and role balance $(r=-.09$, ns). This finding does not lend support for the depletion argument as it pertains to the work-student relationship.

Table 2: Intercorrelations Between the Study Variables among Student's Who Engage in Multiple Roles ( $n=287$ )

\begin{tabular}{|c|c|c|c|c|c|c|c|c|c|c|}
\hline Variable & Mean & s.d. & 1 & 2 & 3 & 4 & 5 & 6 & 7 & 8 \\
\hline 1. Well-Being & 69.67 & 5.21 & - & & & & & & & \\
\hline 2. Time Worked & 27.83 & $\begin{array}{l}12.8 \\
8\end{array}$ &. & - & & & & & & \\
\hline $\begin{array}{l}\text { 3. Time Being a } \\
\text { Student }\end{array}$ & 19.65 & $\begin{array}{l}17.0 \\
3\end{array}$ & -.10 & $-14^{*}$ & - & & & & & \\
\hline 4. Work Satisfaction & 4.94 & 1.28 & -.02 & -.01 & -.12 & - & & & & \\
\hline $\begin{array}{l}\text { 5. Student } \\
\text { Satisfaction }\end{array}$ & 5.03 & 1.20 & -.10 & $\begin{array}{l}- \\
.24^{*}\end{array}$ & .10 & .11 & - & & & \\
\hline 6. WIS & 2.98 & .86 & .03 & $\begin{array}{l}- \\
.32^{*} \\
*\end{array}$ & .06 & $.18^{*}$ & $.27^{*}$ & - & & \\
\hline 7. SIW & 3.28 & .90 & .05 & .10 & -.11 & $.15^{*}$ & $.15^{*}$ & $.37^{*}$ & - & \\
\hline 8. Number of Roles & 2.29 & 52 & .00 & .02 & .00 & .01 & .09 & -.08 & -.01 & \\
\hline 9. Role Quality & 21.49 & 3.11 & -.08 & $.13^{*}$ & .10 & $\begin{array}{l}- \\
.21^{*}\end{array}$ & $-14^{*}$ & $-13^{*}$ & $\begin{array}{l}- \\
.17^{*} \\
*\end{array}$ & -.05 \\
\hline
\end{tabular}

Note: All tests are two-tailed. ${ }^{*} P<.05 .{ }^{* *} p<.01$.

An examination of Table 2 ( $n=287$, students with multiple roles only) reveals a positive significant relationship between time worked and role balance $(r=.13, p<.05)$ and $a$ 
significant negative relationship between time worked and perceiving work interfering with school activities $(r=-.32, p<.01)$. The more hours a student works the greater the role quality and the less they perceive that work interferes with school, thus supporting the enrichment argument. These findings support hypothesis 4 . In addition, hypothesis 5 tests the relationship between the number of hours a student spends in school activities and role balance (quality) and with perceiving school activities interfering with work (SIW). An examination of Table 2 indicates no significant relationships among these variables lending no support to the enrichment argument.

In order to test hypothesis 6 a t-test was performed to test the differences in the means of WIS (M = 2.96) vs. SIW (M = 3.27). Results indicate students who occupy the role of paid worker perceive school interfering with work significantly more than work interfering with school $(\mathrm{t}=-4.79, \mathrm{df}=259, \mathrm{p}<.001)$. These results lend no support to our hypothesis 6 ; in fact it is the reverse. This curious finding is discussed in the next section.

\section{Discussion and Implications}

\section{Discussion}

This research set out to examine how multiple roles may affect the management student's well-being and the importance of role balance, role quality and role conflict in the relationship. The entire sample consisted of students majoring in management. Seventy seven percent were paid workers, either full-time or part-time. The relationship between being a student and a paid worker was of the greatest interest in this research. The research on multiple roles for the work-family relationship guided the theory since little theoretical foundation had been established for the student-work relationship.

The depletion argument implies that the more time one spends in a role may make it more difficult to spend time in other roles which causes role strain, stress, and conflict. The findings in this study tend to support this position. The more time students engage in paid work, the less they reported feelings of well-being. It may be that the workstudent relationship produces strain or stress that is internal and is described as feelings of well-being as Rothbard (2001) suggested. However, researchers also suggested that these findings can be attenuated by feelings of satisfaction. This was not fully supported by this research. No relationship was found between time worked and feelings of work satisfaction. Yet, we did find a relationship between time spent in the student role and student satisfaction. This finding suggests that students may find work as both instrumental and emotional in achieving their goal of acquiring a college education. The way time and work is structured may influence how and what students experience as paid workers. This, of course, will somewhat depend on how they approach being a paid worker: a role often being assumed for the first time. However, in the student role, the more time and effort one can devote to their studies, the greater the feeling of satisfaction. Obviously, the quality of the student role increases as one can increase the amount of time dedicated for learning.

Previous research from the work-family literature indicated that role balance attenuated the relationship between time worked and well-being. The question is whether this 
theory would remain robust in the work-student domain. We approached role-balance from several different perspectives. Initially we investigated the relationship multiple roles may have with well-being and role-balance and surprisingly found no relationship to either. In other words, the number of roles and degree of role balance were not significantly related to a student's sense of well-being. The enhancement argument would suggest otherwise. This finding suggests that students approach multiple roles, especially the role of paid-worker, differently than subjects researched in the workfamily literature. Perhaps it's the level of maturity of the individual, the degree of importance placed on the role of paid-worker and/or being skilled at time management that causes the difference. It was also suggested that there is either an emotional component involved or the lack thereof. Future research will have to determine this.

Next we turned to investigating role-balance in terms of conflict. Here we hypothesized that time worked, and role-balance would be related to WIS and SIW. We found a significant relationship between time worked and role-balance. In addition, a very strong negative relationship emerged between time worked and WIS. Role-balance was also significantly negatively related to SIW. It appears when directly asked about role conflict (e.g. WIS, SIW), role-balance and time are important issues for college students. Unlike time stressors, role-balance doesn't affect their well-being, but does affect their perception of role conflict. Yet, almost no relationship appears to exist between well-being and role conflict (WIS, SIW). This finding is an indication that roleconflict is perceived greater when there is a lack of role-balance in the student's life. If, perhaps, the lack of balance is because of time issues, then students may experience less feelings of well-being, but this issue will have to be investigated in future research.

When we investigated role conflict directly in the working student sample a curious finding occurred. It was hypothesized that working students would perceive work interfering with school more than school interfering with work but the reverse was found. A t-test revealed a very significant mean difference in these scores indicating a definite trend to perceive school interfering more with work. A possible explanation for this surprising finding is that work, for most of this sample, is the means of acquiring an education and without this means an education would not be possible for them.

Somewhat indicating their perception of the importance of both activities is work first, then school. Also business school students usually are aware of the importance of work in one's life and the necessity of earning a good living, and, of course, their ultimate goal is to not only graduate, but to find a good job. Helpful in finding employment is work experience which is encouraged by the university. Interestingly, we did find a significant negative relationship between the amount of time engaged in paid work and level of satisfaction in the student role. This suggests that the opportunity cost of lower student satisfaction as a result of increased time engaged in work is justified by the necessary rewards associated with work. To state it differently, respondents perceive school interfering with work and report lower student satisfaction because work is what enables them to even engage in school. Without the benefits associated with being a paid worker, the role of student would not be an option. Thus, one is willing to sacrifice a degree of student satisfaction in return for the ability to occupy the role of student. 
Although gender differences were not reported to any extent in the work-family literature, we believed that in this age group our subjects were going to perceive stereotypical gender differences in this study. Consistent with the work-family findings no differences were detected between males and females on school and work conflict. However, as expected, females had reported higher GPA's than males. We have come to the conclusion that gender issues are not relevant in this type of research. Whatever differences that existed in the past have narrowed considerably in this century.

\section{$\underline{\text { Implications }}$}

The cost of education is on the rise and universities, including business schools, are in a competitive market for qualified students. Many parents can no longer afford to pay for the entire four years it usually takes to acquire a degree. The student is either put in a position of either getting a scholarship or finding paid work to supplement his or her expenses. This is the most common scenario in our sample of business school students.

The implications for this study center around two significant findings: (1) well-being is related to time engaged as a paid worker and (2) role-conflict is related to role balance for business school students. The first implication is that students' well-being is likely to continue to decline since the cost of an undergraduate education will continue to rise, thus, putting more pressure on students to work longer hours. As time related stressors continue to increase, feelings of well-being are likely to decrease. A student's wellbeing should be a concern for all universities; therefore, attention should be paid to these phenomena. Perhaps academic counselors need to be involved in students' employment decisions and make time management courses mandatory before engaging in paid work and psychological counseling provided for those students who are having a difficult time coping with stress. At the very least, they should be should be made aware of the existence of conflict between paid work and school and the importance role balance plays in this dynamic situation.

Another important implication is that role-balance or quality assists in reducing roleconflict between school and work. It is also positively related to time worked $(r=.13$, $p<.05)$. Students who enjoy more balanced roles have slightly greater feelings of wellbeing and perceive far less conflict than those students with less balanced roles. Rolebalance is a skill that is probably acquired later in a student's developmental cycle and is more likely to be a problem with students engaging in multiple roles. In our sample of students, the conflict emerged with students perceiving school as interfering with work and not the reverse as hypothesized. Are students willing to sacrifice academic achievement for the ability to pay for an education? This question needs to be investigated further. However, role-balance is a skill for which students can also be counseled and trained. Clearly, business school students can benefit from acquiring time and role management skills early, before they enter industry.

Moreover, organizations need to be cognizant of the finding that students sacrifice satisfaction in that role as time engaged as a paid worker increases. One could extrapolate that working students may not benefit from classroom learning to the extent 
that non-working students do and, as a result, may be less versed in a particular area due to the choice of work over school. Rosa Beth Kantor (1977) in her seminal work, "Work and Family..." referred to the "myth of separate worlds" suggesting that managers tend to view an employee as being able to "leave home at home." This same sentiment can be applied to student learning. We should capitalize on their experience in classroom discussions, specifically inviting them to provide the application of theories as well as assisting in bridging of academe to practice. Also, educators need to remember that you get the whole student and if work is on their minds, school will suffer. This has important ramifications for organizations, in terms of recruitment, selection, training and development. Organizations would be well served to review selection plans to ascertain the weight assigned to school and work experience and its appropriateness. The organization is only as good as the people who comprise it.

\section{Limitations}

This research has several limitations that need to be addressed. Firstly, our sample was taken from a university in the North Eastern part of the United States which limits our findings to that part of the country. Though we believe that college students are a homogenous group as such and have many things in common across the country, replications in different geographical locations are necessary to generalize these findings to all college students. Secondly, this was cross-sectional research and as such no causality can be assumed between the hypothesized variables in this study. We can only establish the strength and direction of the relationships and this leaves us with descriptive information and not inferential results. However, we do believe as the initial study on the student-work relationship for college students it was the appropriate place to start. 


\section{References}

American Association of University Women. (1996). Gender gaps. New York: Marlow.

Barnett, R. C. \& Baruch G. K. (1985). Women's involvement in multiple roles and psychological distress. Journal of Personality and Social Psychology, 49, 135-145.

Barnett, R. C., Gareis, K. C., James, J. B., \& Steele, J. (2003). Planning ahead: College seniors' concerns about career-marriage conflict. Journal of Vocational Behavior, 62(2), 305-319.

Barnett, R. C. \& Hyde, J. S. (2001). Women, men, work and family: An expansionist theory. American Psychologist, 56, 781-796.

Barnett, R. C., Marshall, N. L., \& Pleck, J. H. (1992). Men's multiple roles and their relationship to men's psychological distress. Journal of Marriage and Family, 54, 358367.

Bartolome, F., \& Evans, P. A. (1979). Must success cost so much? Harvard Business Review, 58, 137-148.

Bruck,C. S., \& Allen, T. D. (2003). The relationship between big five personality traits, negative affectivity, type A behavior and work-family conflict. Journal of Vocational Behavior, 63, 457-472.

Edwards, J. R. \& Rothbard, N. P. (2000). Mechanisms linking work and family: Clarifying the relationship between work and family constructs. Acadamy of Management Review, 25, 178-199.

Fazio, A. F. (1977). A concurrent validation study of the NCHS General Well-Being Schedule (Dept. of H. E. W. Publ. No. HRA-78-1347). Hyattsville, MD: National Center for Health Statistics.

Goode, W. J. (1960). A theory of role strain. American Sociological Review, 25, 483496.

Greenberger, E., \& O'Neil, R. (1993). Spouse, parent, worker: Role commitments and role related experiences in the construction of adults' well-being. Developmental Psychology, 29, 181-197.

Greenhaus, J. H., \& Beutell, N. J. (1985). Sources of conflict between work and family roles. Academy of Management Review, 10, 76-88.

Kahn, R. L., Wolfe, D. M., Quinn, R. P., Snoek, J. D., \& Rosenthal, R. A. (1964). Organizational Stress: Studies in Role Conflict and Ambiguity. New York: Wiley. 
Kantor, R.M. (1977). Work and Family in the United States: A Critical Review and Agenda for Research and Policy. New York: Russell Sage.

Kopelman, R. E., Geenhaus, J. H., \& Connolly, T. F. (1983). A model of work, family and interrole conflict: A construct validation study. Organizational Behavior and Human Performance, 32, 198-215.

Lobel, S.A. (1991). "Allocation of Investment in Work and Family Roles: Alternative Theories and Implications for Research. Academy of Management Review, 16, 507-21.

Marks, S. R. (1977). Multiple roles and role strain: some notes on human energy, time and commitment. American Sociological Review, 42, 921-936.

Marks, S. R. \& MacDermid, S. M. (1996). Multiple roles and the self: A theory of role balance. Journal of Marriage and Family, 58, 417-432.

Pleck, J. H., Staines, G. L., Lang, L. (1980). Conflicts between work and family life. Monthly Labor Review, 103, 29-32.

Pomerantz, E. M., Altermatt, E. R., \& Saxon, J. L. (2002). Making the grade but feeling distressed: Gender differences in academic performance and internal distress. Journal of Educational Psychology, 94, 396-404.

Rothbard, N. P. (2001). Enriching or depleting? The dynamics of engagement in work and family roles. Administrative Science Quarterly, 46, 655-684.

Rothbard, N. P., \& Edwards, J. R. (2003). Investment in work and family roles: A test of identity and utilitarian motives. Personnel Psychology, 56(3), 699-730.

Stoeva, A. Z., Chiu, R. K., \& Greenhaus, J. H. (2002). Negativity affectivity, role stress and work-family conflict. Journal of Vocational Behavior, 60(1), 1-16. 